\title{
The prevalence of serum antibodies to Ehrlichia ruminantium infection in ranch cattle in Tanzania: a cross-sectional study
}

\author{
E S Swai ${ }^{a^{*}}$, P F Mtui ${ }^{a}$ A K Chang'a ${ }^{b}$ and G E Machange ${ }^{a}$
}

\begin{abstract}
Serum samples collected in a cross-sectional survey of grazing cattle on Manyara Ranch, Monduli district, Tanzania, were tested by indirect major antigenic protein 1 fragment $B$ (MAP 1-B) ELISA to determine the seroprevalence of Ehrlichia ruminantium and to assess ranch-level risk factors for heartwater. Heartwater-exposed cattle were widespread on the ranch and overall seroprevalence was $50.3 \%$ (95\% CI, $44.9-55.6$ ), enough to indicate an endemically unstable situation. Multivariate logistic regression modelling was used to identify risk factors associated with seropositivity. Two factors appeared to increase the herd's risk for contracting heartwater. Seroprevalence increased significantly with age $(\beta=$ 0.19 per year of age, $P<0.001)$ and animals carrying ticks of any species were associated with an increased risk of infection with E. ruminantium (Odds ratio, $\mathrm{OR}=3.3, P<0.001$ ). The force of infection based on the age seroprevalence profile was estimated at 18 per 100 cattle year-risk. The current tick control measures on the ranch were associated with a decreased risk of infection with E.ruminantium $(\mathrm{OR}=0.25$ for no dipping and $\mathrm{OR}=0.31$ for low dipping, $P<0.001)$. Six tick species were identified; in order of frequency these were: Ambylomma variegatum $59.9 \%$, Rhipicephalus evertsi evertsi $13.9 \%$, Rhipicephalus pulchellus $12.5 \%$, Hyalomma truncatum $7.03 \%$ and Rhipicephalus appendiculatus $6.07 \%$. The least encountered tick was Rhipicephalus simus, which accounted for $0.38 \%$. The cattle seemed well adapted to their environment and capable of resisting the tick burden under this extensive wildlife/livestock grazing and interaction system.
\end{abstract}

Key words: E. ruminantium, indigenous cattle, risk factors, seroprevalence, Tanzania.

Swai E S, Mtui P F, Chang'a A K, Machange G E The prevalence of serum antibodies to Ehrlichia ruminantium infection in ranch cattle in Tanzania: a cross-sectional study. Journal of the South African Veterinary Association (2008) 79(2): 71-75 (En.). Veterinary Investigation Centre, PO Box 1068, Arusha, Tanzania.

\section{INTRODUCTION}

Heartwater (cowdriosis), caused by the rickettsial organism Ehrlichia ruminantium (formely Cowdria ruminantium), is an infectious disease of ruminants. The organism is transmitted by 3 host ticks of the genus Amblyomma ${ }^{33}$. Heartwater is one of the most important tick-borne diseases (TBD) affecting both wild and domesticated grazing ruminants in Tanzania ${ }^{18}$, and it has been estimated that the direct economic loss due to the disease is about US\$20.5-24.5 million ${ }^{10}$. The mortality rate due to heartwater is around $15 \%$ with a morbidity rate of $5 \%$, although the severity of the disease varies widely between cattle types, agro-ecological zones, socio-economic conditions and cattle production systems ${ }^{10}$. In tropical and subtropical areas, the disease is endemic and

aveterinary Investigation Centre, PO Box 1068, Arusha Tanzania.

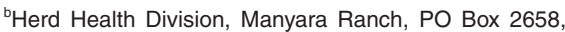
Arusha, Tanzania.

*Author for correspondence.

E-mail: esswai@gmail.com

Received: September 2007. Accepted: April 2008. results in considerable economic losses due to loss of production, treatment costs and reduced initiatives for the upgrading of local breeds of livestock with more susceptible exotic breeds ${ }^{16}$.

Heartwater can be unequivocally diagnosed by the identification of E. ruminantium by demonstration of rickettsial inclusion bodies in the endothelial cells of brain crush smears ${ }^{24}$. This method is, however, only applicable to clinical cases. Serological tests specifically targeting bovines have been applied but are of limited use under field conditions owing to cross-reactions with other Ehrlichia species. ${ }^{6,9}$. The MAP1-B ELISA based on the truncated major antigenic protein 1 of E. ruminantium has been shown to be of value under field and experimental conditions, especially in the regions where the distribution of cowdriosis is unknown $^{14,15,17,33}$.

Although the disease is known to be endemic in various parts of Tanzania, there is very little information on the epidemiology of the disease between and across farming systems in the country. This investigation was designed to provide information on the risk of heartwater and to assist in the development of appropriate control strategies. The prevalence of E. ruminantium was assessed, and factors associated with infection in extensively raised indigenous cattle on Manyara Ranch, Tanzania, were explored.

\section{MATERIALS AND METHODS}

\section{Study site}

Manyara Ranch $\left(03^{\circ} 34^{\prime} 04^{\prime \prime} \mathrm{S}, 36^{\circ} 05^{\prime}\right.$ $\left.01^{\prime \prime} \mathrm{E}\right)$ occupies 17871 hectares $(\sim 45000$ acres) of land and is located $92 \mathrm{~km}$ southwest of Arusha city in the Maasai Steppe Heartland ${ }^{26}$. The ranch is located between 2 major national parks: Tarangire to the south and Lake Manyara to the north. Wildlife and livestock interact freely when grazing. The ranch is semi-arid with annual average rainfall of $600-700 \mathrm{~mm}$ and is at an elevation of $1200 \mathrm{~m}$ above sea level. The vegetation is mainly Acacia-Commiphora bushland, wooded savanna, with short grass. The rains are usually concentrated in 2 seasons: end of March to May, and end of October to December. The mean temperature ranges from 15 to $30{ }^{\circ} \mathrm{C}$. The study was carried out in October and November 2006.

\section{Cattle husbandry system}

The cattle are maintained in a pastoral open grazing system from approximately 07:30 to $16: 30$ daily. No supplementary feeding is provided. The animals are housed at night in bomas or kraals constructed from thorny tree branches to protect them from theft and predators.

The breeding system used on the ranch is natural mating, with service bulls running freely with females year-round. Calves are weaned at 8 months of age. Young calves are isolated and penned until the return of their dams from grazing, and then allowed to suckle. Cattle are vaccinated yearly against anthrax, haemorrhagic septicaemia, lumpy skin disease, and female calves $<10$ months of age with Brucella Strain 19. Control of ectoparasites, mainly ticks, is carried out by using 
Decatix ${ }^{\circledR}(2.5 \% \mathrm{~m} / \mathrm{v}$, Deltamethrin, Coopers, Zimbabwe). The frequency of dipping is coded as follows: none: no dipping, low: once every 4 weeks; moderate: twice every 4 weeks. Anthelmintic treatment using Albendazole (10\%, Kela N.V., Phenix, Belgium) is generally limited to calves.

\section{Study animals and sampling}

A systematic sampling procedure was adopted and every 4 th animal was selected as the cattle passed through a crush ${ }^{2}$. A total of 360 cattle (all ages and sexes), out of the total ranch herd size of 1481, were used in the study. The cattle types reared on the ranch are Boran (75 \%) and Tanzania short horn zebu (TSHZ) $(20 \%)$, and their crosses (5\%). Each selected animal was subjected to a thorough, whole-body inspection for the presence of ticks. Other information recorded included: sex, age (estimated by ear notch, examination of teeth and written records). The age of each animal was transformed age centred to normalise the data. Tick infestation, with both mature and immature stages, was coded as low: $\leq 20$; moderate: $>20$ and $\leq 40$; high: $>40$. Tick infestation was moderate, therefore whole body counting was adopted ${ }^{8}$. Ticks on the study animals were identified to genera and species and counted using standard procedures $^{8}$. The body condition score of each sampled animal was determined using the 9-point system developed at the International Livestock Centre for Africa $^{20}$. Scores were categorised as $\geq 1-3$ : thin; $\geq 4-6$ medium; and $\geq 7-9$ : fat. The responses to many of these questions were investigated as explanatory variables in the analyses of seroconversion to E. ruminantium.

\section{Collection of sera and laboratory analysis}

Blood samples for sera were collected aseptically by jugular venipuncture into a plain vacutainer tube (Becto-Dickson, UK) from selected animals. The blood samples were labelled and transported in refrigerated cool boxes to the Veterinary Investigation Centre (VIC) laboratory where they remained overnight. Serum was then separated by centrifugation and stored at $-20^{\circ} \mathrm{C}$ until used. The sera were analysed for antibodies against E. ruminantium using indirect MAP1-B ELISA ${ }^{15,34}$. The results were expressed as per cent positive (PP) calculated as a percentage of the optical density (OD) value of the reference positive control. The cut-off point was obtained by plotting a graph of the OD readings of heartwater-negative sera. Seroconversion status was considered positive if the PP cut-off was $\geq 20 \%{ }^{33}$

\section{Statistical analysis}

Descriptive statistics for the animal and ranch-level explanatory variables (inclusive of tick infestation) examined in the study were developed using Epi-Info version $6.04 \mathrm{~d}^{7}$. Cross-correlations ${ }^{7}$ were performed on all explanatory variables to investigate the potential for confounding amongst them (defined as those with a coefficient of 0.7 or greater). The relationship between explanatory variables and outcome response (seroconversion to E. ruminantium) were investigated in 2 steps by logistic regression (using Egret for Windows ${ }^{4}$ version 2.0). Explanatory variables investigated were 'presence of a tick of each species' investigated as a binary variable (i.e. yes or no); body score (coded as fat, medium, thin); dipping (yes or no), acaricide application frequency (coded as none, low, moderate); sex (female or male) and age.

In the 1st step, the relationships between each explanatory and outcome variable were individually investigated. In the 2nd step, any variables that were significantly associated at $P<0.25$ were included in multivariate logistic regression ${ }^{4}$ models, producing, by forwards and backwards substitution and elimination, the most parsimonious models in which all explanatory variables remained significant at the $P<0.05$ level. The criteria for inclusion and exclusion were a change in deviance significant at the $5 \%$ level according to the maximum likelihood ratio test-chi square distribution.

Forces of infection were estimated from age seroprevalence profiles using maximum likelihood methods (MLM) in Excel (Microsoft, USA) with the Solver add-in ${ }^{29}$. Assuming a stable population size and age structure and a constant force of infection across all age groups, the log likelihood (LL) was derived using the following equation:

$$
L L=\sum_{i=1}^{a} R_{i} \ell n e^{-\lambda i}+\left(N_{i}-R_{i}\right) \ln \left(1-e^{-\lambda i}\right)
$$

where $R_{i}=$ number of seropositive in group $i, N_{i}=$ number tested in age group $i$ and $\lambda=$ the force of infection.

\section{RESULTS}

\section{Descriptive analysis of antibody response to $E$. ruminantium}

Of the animals sampled $(n=360), 249$ $(69.2 \%)$ were females and $111(30.8 \%)$ were males. The mean serum antibody prevalences of the 360 animals studied by variable categories are shown in Table 1. The overall mean antibody prevalence was $50.3 \%$ (95\% CI, 44.9 -55.5).

\section{Tick infestation}

A total of 2600 ticks (mature and immature) were counted during sampling. Of the 360 cattle examined and sampled, 320 were found to carry ticks, giving an infestation rate of $88.9 \%$ and the overall mean (mean \pm SE) tick density of $8.12 \pm 0.44$ tick/cattle. Tick infestation rate was significantly $\left(\chi^{2}=31.7, \mathrm{df}=4, P=0.001\right)$ higher in low, intensive and non-dipped and least in moderately dipped cattle. The mean tick-specific densities per animal are detailed in Table 2.

Six tick species were identified, with A. variegatum being the most abundant (59.9\%), followed by $R$. evertsi evertsi (13.9\%), R. pulchellus (12.5\%), H. truncatum $(7.03 \%)$ and $R$. appendiculatus $(6.07 \%)$. The least encountered tick was R. simus at $0.38 \%$.

\section{Age-antibody prevalence profiles}

An increasing seropositivity was recorded with respect to increasing age. The estimated force of infection was at 0.18 animals per cattle year-risk. The graphical age seropositivity relationship and forces of infection are shown in Fig. 1.

\section{Factor influencing antibody response to E. ruminantium}

The factors that were significantly associated with E. ruminantium antibody prevalence in the multivariate regression model are given in Table 3. Cattle treated with acaricide at an interval of once per month and not dipped were associated with significantly lower antibody prevalence than those that were treated at an interval of twice per month $(\mathrm{OR}=0.31$ for once per month, $\mathrm{OR}=0.25$ for not dipped, $P<$ 0.001 ). Animals that carried ticks (of any species) at the time of survey were associated with significantly higher seropositivity than those that did not carry ticks $(\mathrm{OR}=3.30, P<0.001)$. Multivariate analysis of risk factors showed that age was the risk factor for the occurrence of seropositivity to heartwater in cattle $\beta=$ 0.19 per year of age, $P<0.001)$.

\section{DISCUSSION}

Based on a serological survey, the present investigation revealed that bovine cowdriosis due to E. ruminantium infection exists on Manyara Ranch, supporting the presence of heartwater (cowdriosis) (A Chang'a, pers. obs., 2006) and in other parts of Tanzania ${ }^{10,13}$. The detected prevalence of infection in the cattle was intermediate in comparison to that observed in other studies in Africa; from $31 \%{ }^{11}$ in the Ivory Coast, $41 \%$ in Malawi ${ }^{25}$, and up to $61 \%$ in Ghana ${ }^{12}$, but generally higher than observed in studies in Caribbean, e.g. from $7.3 \%$ reported in indigenous 
cattle on 19 islands ${ }^{19}$ to $30 \%$ in cattle in Guadeloupe $^{3}$. The estimated seroprevalence was considerably less than $70 \%$, suggesting that this pathogen exists in a state of 'endemic instability' as defined ${ }^{5,21}$. However, these levels are sufficiently high to ensure that clinical disease would be a risk.

The most commonly detected tick species was $A$. variegatum, which was consistent with serological responses to E. ruminantium (transmitted by $A$. variegatum), having the highest prevalence amongst the cattle ${ }^{13,25}$. R. evertsi evertsi constituted $13.9 \%$ and was the 2nd-most abundant tick. However, this result is not consistent with findings in Ethiopia, where it formed only $6.4 \%$ of the total ticks counted in a survey ${ }^{28}$. The ability of this tick to survive in open grassland, comparable to Manyara Ranch, and its perennial breeding habit, have both been advanced as the reasons for high incidences. Tick burdens were low (mean 8.2, range 4-64), but with no adult ticks of any species being observed on cattle in $11 \%$ of observations. Such low tick burdens could reflect the poor off-host survival of ticks in cattle ranchland.

The present study indicated that animals that were not dipped, and those dipped at an interval of once every 4 weeks, were all associated with lowered seropositivity. It is not clear, however, why the detected rate of infection was low, particularly for undipped cattle, considering the number and level of tick infestation recorded during the survey. One possible explanation could be that the current acaricide (at least at ranch level) regimen (once every 4 weeks, and twice every 4 weeks) is more frequent than necessary, although it might not necessarily be true because of other tick species that are potential vectors of other tick-borne diseases. It is not clear, therefore, to what extent these cattle contribute to the maintenance of ticks and the E. ruminantium pathogen on Manyara Ranch, and this warrants further investigation.

Presence of vectors (ticks) was another factor associated with cattle seropositive
Table 1: List of variables, proportion and seroprevalence of each category investigated $(n=$ 360) $(\mathrm{Cl}=$ confidence interval).

\begin{tabular}{|c|c|c|c|}
\hline Variable & Category & $\begin{array}{l}\text { Number of animals } \\
(\%)\end{array}$ & $\begin{array}{l}\text { Seroprevalence \% } \\
\quad( \pm 95 \% \mathrm{Cl})\end{array}$ \\
\hline Score & $\begin{array}{l}\text { Fat } \\
\text { Medium } \\
\text { Thin }\end{array}$ & $\begin{array}{c}298(82.8) \\
49(13.6) \\
13(3.6)\end{array}$ & $\begin{array}{l}48.6(42.8-54.4) \\
61.2(46.2-74.8) \\
46.2(19.2-74.8)\end{array}$ \\
\hline Sex & $\begin{array}{l}\text { Female } \\
\text { Male }\end{array}$ & $\begin{array}{l}249(69.2) \\
111(30.8)\end{array}$ & $\begin{array}{l}58.2(51.8-64.4) \\
32.4(23.8-41.9)\end{array}$ \\
\hline Age (in years) & $\begin{array}{l}\geq 0.5 \text { to } \leq 1.5 \\
>1.5 \text { to } \leq 3.0 \\
>3.0 \text { to } \leq 4.5 \\
>4.5 \text { to } \leq 6.0 \\
>6.0 \text { to } 9.0\end{array}$ & $\begin{array}{c}101(28.05) \\
102(28.3) \\
80(22.2) \\
56(15.5) \\
21(5.8)\end{array}$ & $\begin{array}{l}30.6(21.8-40.6) \\
41.1(31.5-51.3) \\
67.5(56.1-77.5) \\
66.07(52.1-78.1) \\
80.9(58.0-94.5)\end{array}$ \\
\hline Dipping & $\begin{array}{l}\text { Yes } \\
\text { No }\end{array}$ & $\begin{array}{c}328(91.1) \\
32(8.9)\end{array}$ & $\begin{array}{l}53.3(47.4-58.5) \\
21.8(9.2-39.9)\end{array}$ \\
\hline Acaricide & $\begin{array}{l}\text { None } \\
\text { Low } \\
\text { Moderate }\end{array}$ & $\begin{array}{c}32(8.2) \\
96(26.7) \\
232(64.4)\end{array}$ & $\begin{array}{l}21.8(9.2-39.9) \\
29.1(20.3-39.3) \\
62.9(56.3-69.1)\end{array}$ \\
\hline Carrying tick (of any sp.) & $\begin{array}{l}\text { Yes } \\
\text { No }\end{array}$ & $\begin{array}{r}320(88.9) \\
40(11.8)\end{array}$ & $\begin{array}{l}51.8(46.2-57.4) \\
37.5(22.7-54.1)\end{array}$ \\
\hline $\begin{array}{l}\text { Tick spp. }(n=320) \\
\text { A. variegatum }\end{array}$ & $\begin{array}{l}\text { Yes } \\
\text { No }\end{array}$ & $\begin{array}{r}278(86.8) \\
42(13.1)\end{array}$ & $\begin{array}{l}50.3(44.3-56.3) \\
49.3(38.7-61.2)\end{array}$ \\
\hline R. evertsi evertsi & $\begin{array}{l}\text { Yes } \\
\text { No }\end{array}$ & $\begin{array}{l}133(41.6) \\
187(58.4)\end{array}$ & $\begin{array}{l}44.3(35.7-53.2) \\
53.7(47.0-60.3)\end{array}$ \\
\hline H. truncatum & $\begin{array}{l}\text { Yes } \\
\text { No }\end{array}$ & $\begin{array}{l}93(29.06) \\
227(70.9)\end{array}$ & $\begin{array}{l}49.4(38.9-60.03) \\
50.6(44.4-56.7)\end{array}$ \\
\hline R. pulchellus & $\begin{array}{l}\text { Yes } \\
\text { No }\end{array}$ & $\begin{array}{l}146(45.6) \\
174(54.3)\end{array}$ & $\begin{array}{l}45.9(37.7-54.3) \\
53.3(46.3-60.1)\end{array}$ \\
\hline R. appendiculatus & $\begin{array}{l}\text { Yes } \\
\text { No }\end{array}$ & $\begin{array}{r}50(15.6) \\
270(84.4)\end{array}$ & $\begin{array}{l}42.0(28.1-56.7) \\
51.6(45.8-57.2)\end{array}$ \\
\hline
\end{tabular}

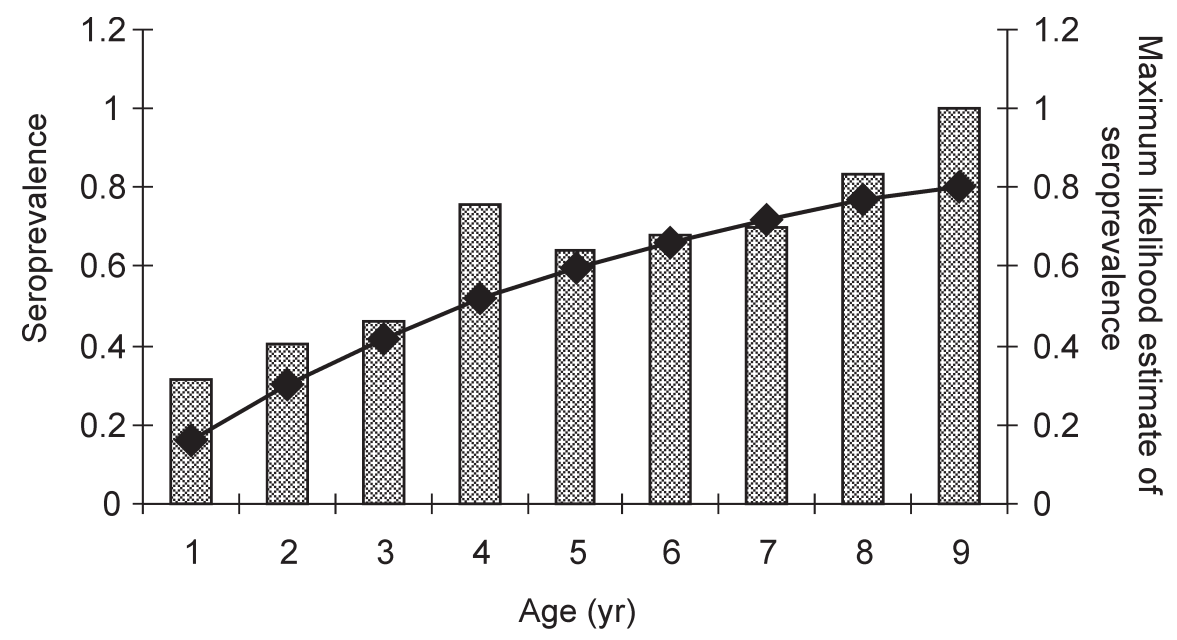

Fig. 1: Age seroprevalence and maximum likelihood force of infection estimate $(\lambda=0.18)$ for Ehrlichia ruminantium on Manyara Ranch.

Table 2: Number of infested cattle and infestation rate and density of 7 tick species.

\begin{tabular}{lcrr}
\hline Tick species & $\begin{array}{c}\text { No. of cattle infested } \\
(\%)\end{array}$ & $\begin{array}{c}\text { Infestation rate } \\
\text { (mean } \pm \text { SE) }\end{array}$ & Tick density \\
\hline A. variegatum & 278 & 77.2 & $5.60 \pm 0.344$ \\
R. evertsi evertsi & 133 & 36.9 & $2.72 \pm 0.195$ \\
R. pulchellus & 148 & 41.1 & $2.20 \pm 0.128$ \\
H. truncatum & 93 & 25.8 & $1.96 \pm 0.152$ \\
R. appendiculatus & 50 & 13.9 & $3.16 \pm 0.478$ \\
R. simus & 7 & 1.9 & 326 \\
Overall & 320 & 88.9 & $1.42 \pm 0.202$ \\
\end{tabular}


Table 3: Significant factors associated with seropositivity to Ehrlichia ruminantium of cattle on Manyara Ranch using multivariable logistic models $\beta=$ coefficient of regression (or parameter estimate), $\mathrm{SE}=$ standard error of coefficient, $\mathrm{LRS}=$ likelihood ratio statistic, $\mathrm{LRP}=$ likelihood ratio $P$-value)

\begin{tabular}{llllll}
\hline Variable $\quad \beta(\mathrm{SE})$ & Wald P & LRS & LRP & $\begin{array}{c}\text { Odds } \\
\text { ratio } \\
( \pm 95 \% \mathrm{Cl})\end{array}$ \\
\hline
\end{tabular}

\begin{tabular}{lcllll}
\hline $\begin{array}{l}\text { Constant } \\
\text { Application frequency: }\end{array}$ & $-0.61(0.33)$ & & & & \\
Low vs moderate & $-1.17(0.32)$ & 0.001 & 61.5 & 0.001 & $0.31(0.16-0.58)$ \\
None vs moderate & $-1.35(0.53)$ & 0.001 & & & $0.25(0.09-0.73)$ \\
Carrying tick: yes vs no & $1.19(0.36)$ & 0.001 & & 0.001 & $3.30(1.61-6.76)$ \\
Age (centred) in years & $0.19(0.079)$ & 0.001 & & 0.001 & $1.21(1.03-1.42)$ \\
\hline
\end{tabular}

to E. ruminantium. Animals that carry ticks (of any species) had higher seroprevalence since they were at a higher risk of exposure than those that had no ticks. Other factors investigated such as body score were not associated with E.ruminantium infection.

Age-related differences in prevalence and force of infection were significant. A strong positive correlation was observed with increasing age and reactor rates, reflecting more innate resistance to primary infection and a high level of exposure to infective ticks. This is in agreement with the findings of other authors ${ }^{32}$. High antibody response to the E. ruminantium parasite in animals above 6 months of age (the youngest animals sampled) demonstrated a high level of and early exposure to infective ticks consistent with a high degree of infection. Studies have shown that maternally derived antibodies decline to zero within 2-4 months ${ }^{1}$. In the light of our findings, the detected antibody titres could be due to field exposure to infective ticks rather than maternally derived antibodies. As far as is known, immunisation against E. ruminantium has never been carried out in Tanzania, and any seropositive cattle are most likely to have been naturally infected. Nonetheless, this is the first structured study to have identified and quantified the determinants of heartwater in an extensively grazed local herd in rural Tanzania.

Although MAP-1B ELISA is rated as more specific and sensitive to ovine and caprine than bovine sera compared to polyclonal competitive ELISA (PCELISA $)^{27}$, our seroconversion estimates are likely to be lower or higher than the true prevalence in the cattle. A wider use of MAP-1B-ELISA in cattle under field conditions is hampered by the down- regulation of antibody responses to E. ruminantium following 1st exposure to the organism, and also by cross-reactions with other Ehrlichia secies such as E. canis and E. phagocytophilum ${ }^{22,23}$. However, consistent with the results of Zimbabwean study ${ }^{14}$, the findings of this study did provide evidence of previous exposure to the pathogen and suggest that there is a need for strict tick-control measures. The serological evidence of cattle exposure to E. ruminantium infection highlights the need for taking cowdriosis into consideration in the envisaged future crossbreeding scheme on Manyara Ranch, where over $70 \%$ of the ranch herd is of the Boran breed. This breed has been shown to have a higher growth rate and reproductive performance, and better adaptability to stressful nutritional, parasitic and disease conditions, than the exotic (Bos taurus) breed $^{30}$. These potentials have made Boran cattle a standard breed in crossbreeding for both beef and milk production in low-input pasture-based systems ${ }^{31}$

\section{CONCLUSIONS}

The use of serum antibody profiles in the detection of exposure of cattle to the E. ruminantium parasite has an important diagnostic role. Despite the fact that animals seem well adapted to ranch environments, the use of antibody profiles alone is not adequate to explain disease status, as a number of animals developed antibodies without obvious clinical disease. Consistent with serology, other prospective morbidity and mortalitity studies should be carried out to arrive at a better-informed indication of the disease status in this complex livestock/wildlife interaction system.

\section{ACKNOWLEDGEMENTS}

The authors gratefully acknowledge FAO country office in Tanzania for financing the E. ruminantium serology kit. We are also grateful to the manager of Manyara Ranch, who kindly allowed us to use his ranch and facilities. My sincere thanks go to Drs A. Nijhof and B. Faburay for reviewing an earlier draft of this paper and for providing useful suggestions. This paper is published with the permission of the Director of the Veterinary Services in Tanzania.

\section{REFERENCES}

1. Bell-Sakyi L, Koney E B, Dogbey O, Walker A R 2004 Ehrlichia ruminantium seroprevalence in domestic ruminants in Ghana; I. Longitudinal survey in the Greater Accra Region. Veterinary Microbiology 100: 175-188

2. Cameron A 1999 A practical manual and software package for active surveillance of livestock diseases in developing countries. ACIAR Monograph No. 4, Canberra, Australia

3. Camus E, Martinez D, Beauperthuy L, Benderdouche A, Coisne S, Corbette C, Denormandie N, Garris G, Harris D, King T 1993 Heartwater in Guadeloupe and in the Caribbean. Revue d'Élevage et de Médecine Vétérinaire des Pays Tropicaux 46: 109-14

4. Cytel Software Corporation 1999 Statistics and Epidemiology Research Corporation, version 2.0. Seattle, USA

5. Deem S L, Perry B D, Katende J M, McDermott J J, Mahan S M, Maloo S H, Morzaria S P, Musoke A J, Rowlands G J 1993 Variations in prevalence rates of tick-borne diseases in zebu cattle by agro ecological zone - implications for East-coast fever immunization. Preventive Veterinary Medicine 16: 171-187

6. Du Plessis J L, Bezuidenhout J D, Brett MS, Camus E, Jongejan F, Mahn S M, Martinez D 1993 The sero-diagnosis of heartwater: a comparison of five tests. Revue d'Élevage et de Médecine Vétérinaire des Pays Tropicaux 46: 123-129

7. Epi-info 1996 Centres for Disease Control, version 6.04d, Atlanta, USA, and Geneva, Switzerland

8. Hoogstraal H 1956 African Ixodoidea Volume 1. Ticks of Sudan. Department of the Navy, Bureau of Medicine and Surgery, Washington, DC

9. Jongejan F, Thielemans M J 1989 Identification of an immunodominant antigenically conserved 32-kilodalton protein from Cowdria ruminantium. Infection and Immunity 57: 3243-3246

10. Kivaria F M 2006 Estimated direct economic costs associated with tick borne diseases on cattle in Tanzania. Tropical Animal Health Production 38: 291-299

11. Knopf L, Komoin-Oka C, Betschart B, Jongejan F, Gottstein B, Zinsstag J 2002 Seasonal epidemiology of ticks and aspects of cowdriosis in $\mathrm{N}^{\prime}$ dama cattle in the central Guinea Savannah of Côte d'Ivoire. Preventive Veterinary Medicine 53: 21-30

12. Koney E B, Dogbey O, Walker A R, Bell-Sakyi L 2004. Ehrlichia ruminantium seroprevalence in domestic ruminants in Ghana. II. Point prevalence survey. Veterinary Microbiology 103: 183-193

13. Lynen G, Bakuname C, Sanka P 1999 Tick and tick borne survey in northern regions of Tanzania. Proceedings of the Tanzanian Veterinary Association (TVA) Scientific Conference held at AICC Arusha, 30 November - 2 December 1999: 24-31

14. Mahan S M, Semu S M, Peter T F, Jongejan F 1998 Evaluation of the MAP-1B ELISA for cowdriosis with field sera from livestock in Zimbabwe. Annals of the New York Academy of Sciences 849: 259-261

15. Mboloi M M, Bekker C P, Kritwagen C, Grener M, Jongejan F 1999 Validation of the indirect MAP 1B enzyme-linked immunosorbent assay for diagnosis of experimental Cowdria ruminantium infection in small ruminants. Clinical and Diagnostic Laboratory Immunology 6: 66-72 
16. Meltzer MI, Norval RA 1993 Evaluating the economic damage threshold for bont tick (Amblyomma hebraeum) control in Zimbabwe. Experimental and Applied Acarology 17: 171185

17. Mondry R, Martinez D, Camus E, Liebisch A, Katz J B, Dewald R, Van Vliet A H, Jongejan F 1998 Validation and comparison of three enzyme-linked immunosorbent assays for detection of antibodies to Cowdria ruminatium. Annals of the New York Academy of Sciences 849: 262-272

18. Mtei B M, Msami H 1998 Tick and tickborne disease control. Strategy paper of the Livestock Department, Ministry of Agriculture. Vol. 1, Dar es Salaam, Tanzania

19. Muller K A, Martinez D, Camus E, Jongejan F 1992 Distribution of heart water in the Caribbean determined on the basis of detection of antibodies to the conserved 32-kilodalton protein of Cowdria ruminantium. Journal of Clinical Microbiology 30: 1870-1873

20. Nicholson M J, Butterworth M H 1986 A guide to condition scoring of zebu cattle. International Livestock Centre for Africa, Addis Ababa, Ethiopia

21. Norval R A I, Lawrence A J, Young A S, Perry B D, Dolan T T, Mukhebi W A, Bishop, R, McKeever D 1992 The epidemiology of theileriosis in Africa. Academic Press, London

22. Peter T F, Mahan S M, Burridge M J 2002
Ehrlichia ruminantium infection (heartwater) in wild animals. Trends in Parasitology 18: 214-218

23. Semu S M, Peter T F, Mukwedeya D, Barbet A F, Jongejan F, Mahn S M 2001 Antibody responses to MAP $1 \mathrm{~B}$ and Cowdria ruminantium antigen are down regulated in cattle with tick transmitted heart water. Clinical and Diagnostic Laboratory Immunology 8: 388-396

24. Smith G E, Anderson E C, Burridge M J, Peter T F, Mahan S M 1998 Growth of Cowdria ruminantium in tissue culture endothelial cell lines from wild African mammals. Journal of Wildlife Diseases 34: 297-304

25. Soldan A W, Norman T L, Masaka S, Paxton E A, Edelsten R M, Sumption K J 1993 Sero-conversion to Cowdria ruminantium of Malawi zebu calves, reared under different tick control strategies. Revue d'Élévage et de Médecine Vétérinaire des Pays Tropicaux 46: 171-177

26. Sumba D, Bergin P, Jones C 2005 Land conservation trusts: a case study of Manyara ranch. AWF working paper. Online at: http://www.awf.org (accessed July 2007)

27. Sumption K J, Paxton E A, Bell-Sakyi L 2003 Development of a polyclonal competitive enzyme-linked immunosorbent assay for detection of antibodies to Ehrlichia ruminantium. Clinical and Diagnostic Laboratory Immunology 10: 910-916
28. Tafesse B 1996 Survey on the distribution of ticks of domestic animals in eastern Ethiopia. Tropical Animal Health Production 28: 145-146

29. Thrusfield M 2000 Veterinary epidemiology. Blackwell Science, London

30. Trail J C M, Gregory K E, Marples H J, Kakonge J 1982 Heterosis, additive maternal and additive direct effects of the Red Poll and Boran breeds of cattle. Journal of Animal Science 54: 517-523

31. Trail J C M, Gregory K E, Stanford J, Durkin J 1984 Crossbreeding cattle in beef production programmes in Kenya. I. Comparison of purebred Boran and Boran crossed with the Chorolais, Aryshire and Santa Gertrudis breeds. Tropical Animal Health Production 16: 181-186

32. Trueman KF, Blight GW 1978 The effects of age on the resistance of cattle to Babesia bovis. Australian Veterinary Journal 54: 301305

33. Uilenberg G 1997 The epidemiology of heartwater: establishment and maintenance of endemic stability - two comments. Parasitology Today 13: 243

34. Van Vliet A H, van der Zeijst B A, Camus E, Mahan S M, Martinez D, Jongejan F 1995 Use of a specific immunogenic region on the Cowdria ruminantium MAP1 protein in a serological assay. Journal of Clinical Microbiology 33: 2405-2410 